\title{
AE TEST OF CALCAREOUS SANDS WITH PARTICLE RUSHING
}

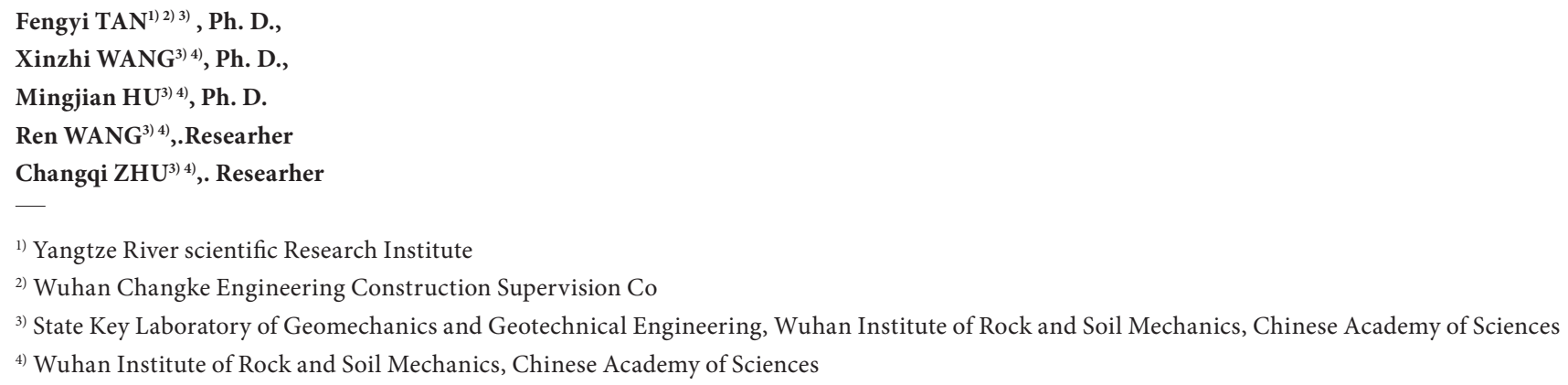

\begin{abstract}
The particle of calcareous sands was forced to crush, then the energy from the crushing was released by the form of sound waves. Therefore the AE technique was used to detect the calcareous sands AE signal when it crushed. by to study the AE characteristics, the mechanics of calcareous sands was studied. Study showed that: (1) there was the $A E$ activities on the low confining pressure condition at the beginnig of test, (2) there was more and more AE activities with the continuing of test until to the end, (3) the calcareous sands' AE activities was on the whole testing, (4) the calcareous sands' particle crushing and mutual friction played different roles for its $A E$ activities. Then the AE model based on the calcarous sands' particle crushing was discussed.
\end{abstract}

Keywords: Calcareous sands, Accoustic emission, Conventional triaxial, Consolidated undrained, AE signal, Particle crushing

\section{INTRODUCTION}

The acoustic emission (AE) technique was widely used in the rock mechanics tests at home and abroad, which was also used in the in-situ stress testing, monitoring for the rock stability during the dam construction, the slide and the drilling, etc. with abundant accomplishment $[1,2]$.

The AE technique was introduced in the geotechnical field by R.M. Koerner as the representative of a group of scholars. They made the important contribution to soil's AE characteristics and related monitoring since 1970s [3-16]. R.M.Koerner studied the conhesionless soil's AE characteristics in 1976, Tanimoto studied the sandy soil's AE characteristics under the condition of triaxial compression test, Villet et al studied the AE signal during the cone penetration test, Koerner studied the AE signal under the condition of preconsolidation pressure in 1984, Tanimoto obtained the AE signal of yield stress in soil layer in 1986, Deutsch and Koerner studied the field determination of AE method under the condition of preconsolidation pressure in 1989, Bingfeng XU studied the soil's AE characteristics under the condition both of the uniaxial compression and the triaxial compression, from the dislocation and energy point of view, he deduced the soil's dislocation source and the relationship between the variation of strain energy and $\mathrm{AE}$ parameters[3, 17].

Calcareous sands is the marined origin geomaterials with richful calcium carbonate or other insoluble carbonate 
componants[1]. It is mainly distributed in the continenal shelf and coastline with the tropics or subtropics between the north altitude 30 degree and south altitude 30 degree, particularly in the islands of South China Sea, the Red Sea, Southern Arabian Gulf, Western Indian Ocean, the continental shelf of Western Australia, Florida waters in North America, Central American Ocean, Barbados and so on.

The calcareous sands is from the ocean and the Terrestrial Sedimentary Environment, particularly in the seabed of tropical shallow sea. The sedimentary origin of calcareous sands is from the following: skeleton of calcareous organisms, clastic fragment and the sendimentary from the carbonate materials in the ocean due to the changes of enviromental factors including temperature, pressure and so on. There are four main forms of calcareous sand particles, skeleton granule, Shale particle, fragment and grain. In South China Sea, the coral debris are the main composition of the calcareous sands, its partcle is skeleton granule.

Due to its richful calcium carbonate with no less than $96.7 \%$, the particle cruching of calcarous sands was occurred under the lower stress state[19-22]. The above study showed that there were AE activities for noncohesive soil, cohesive soil and sandy soil under the certain conditions. The particle of calcareous sands was forced to crush, then the energy from the crushing was released by the form of sound waves. Therefore the $\mathrm{AE}$ technique was used to detect the calcareous sands $\mathrm{AE}$ signal when it crushed. by to study the AE characteristics, the mechanics of calcareous sands was studied.

\section{AE TEST OF CALCAREOUS SANDS}

There was the consolidated undrained triaxial test at the conventional strain controlled triaxial shear apparatus, which was composed by four systems: the testing machine, the pressure chamber, the measuring and controlling System and the sample preparation system, shown in figure 1 . It was used to obtain the parameters such as the total shearing strength and the effective strength, and according to the different drainage conditions, there were the unconsolidated undrained triaxial test, the consolidated undrained triaxial test and the the consolidated drained triaxial test.

AE data acquistion system was the Aewin E1.86 acoustic emission detector with 16 channels, which was composed by three system: sensors, amplifier, and analysing system with the following functions respectively: to receive the AE signal, to process the received signals and to display the processed signals. There were three different channel types: the accoustic emission detector with one channel, double channels or the multiple channels.

The figure 2 was the the Aewin E1.86 acoustic emission detector with 16 channels for tests

The Acquisition system of Aewin E1.86 acoustic emission detector out of operation was shown in figure 3.

The diameter and height of R15 sensors was $18.0 \mathrm{~mm}$ and $17.0 \mathrm{~mm}$ respectively, its parameters were the following: resonance frequency was $150.0 \mathrm{kPa}, 10 \mathrm{~dB}$ frequency band was between $60.0 \sim 250.0 \mathrm{kHz}$, absolute activity was no less than $65 \mathrm{~dB}$.

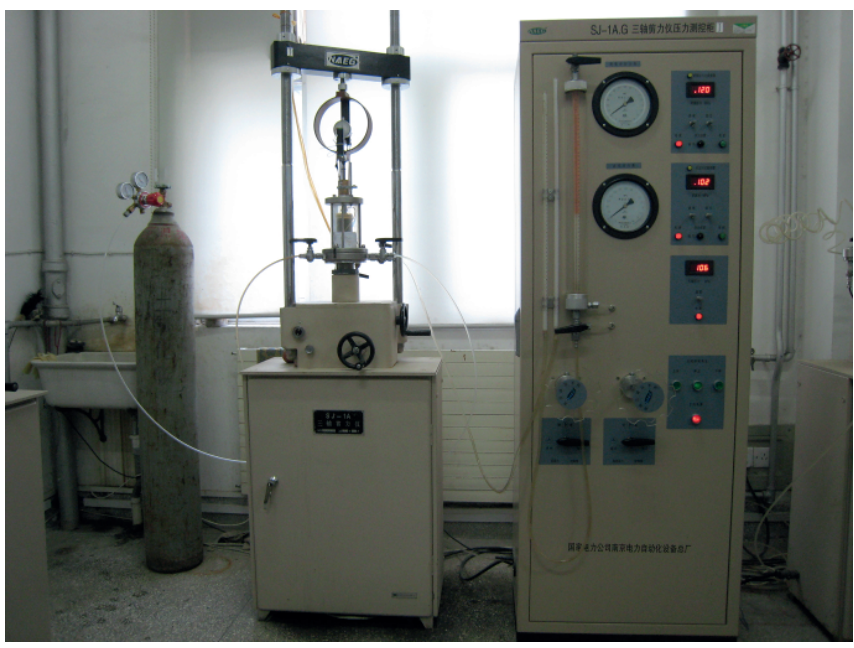

Fig. 1. SI-1A.G triaxial shear apparatus

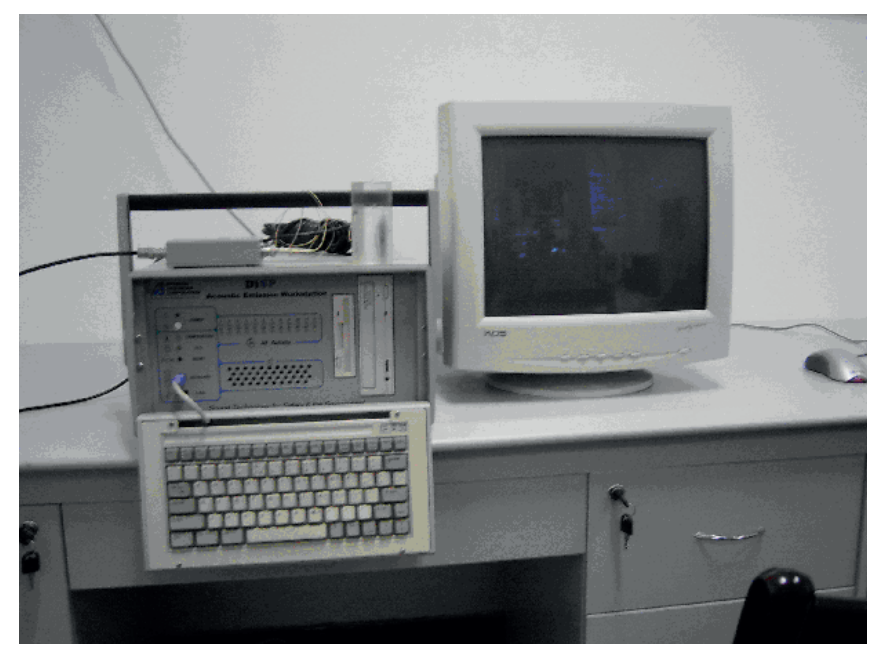

Fig. 2. Aewin E1.86 acoustic emission detector with 16 channels

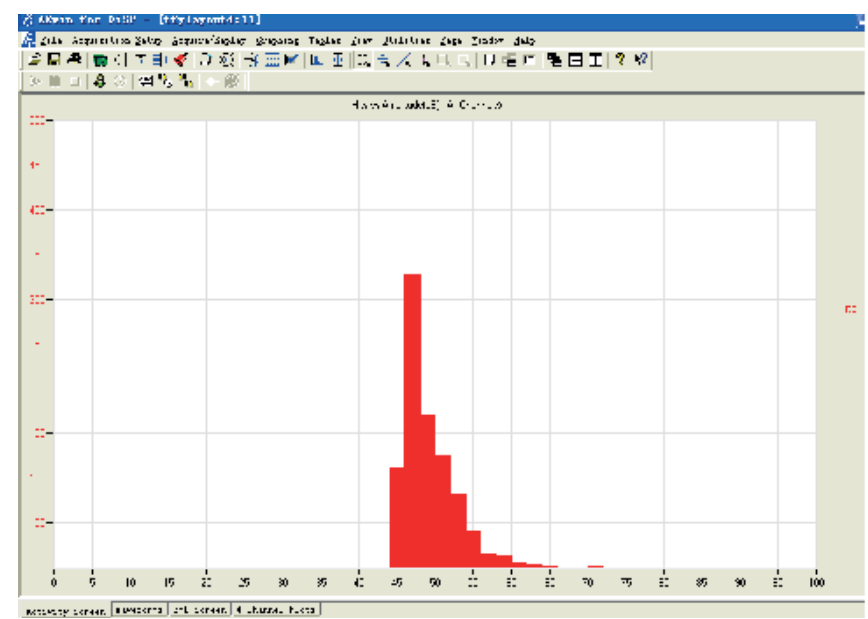

Fig. 3 Acquisition system of Aewin E1.86 acoustic emission detector out of operation 


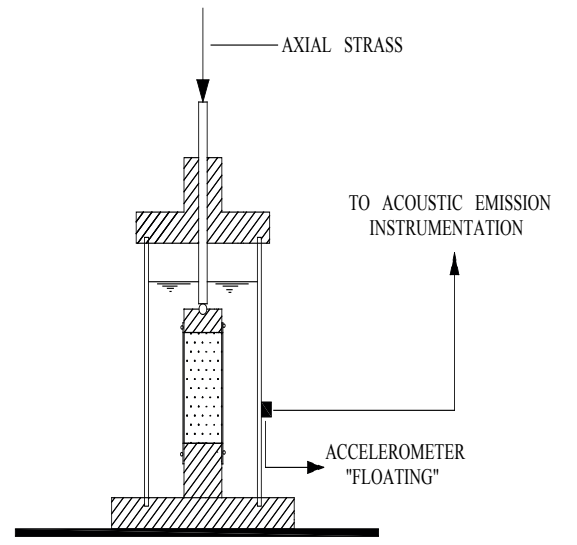

Fig. 4. Diagram of acoustic emission testing of calcareous sand

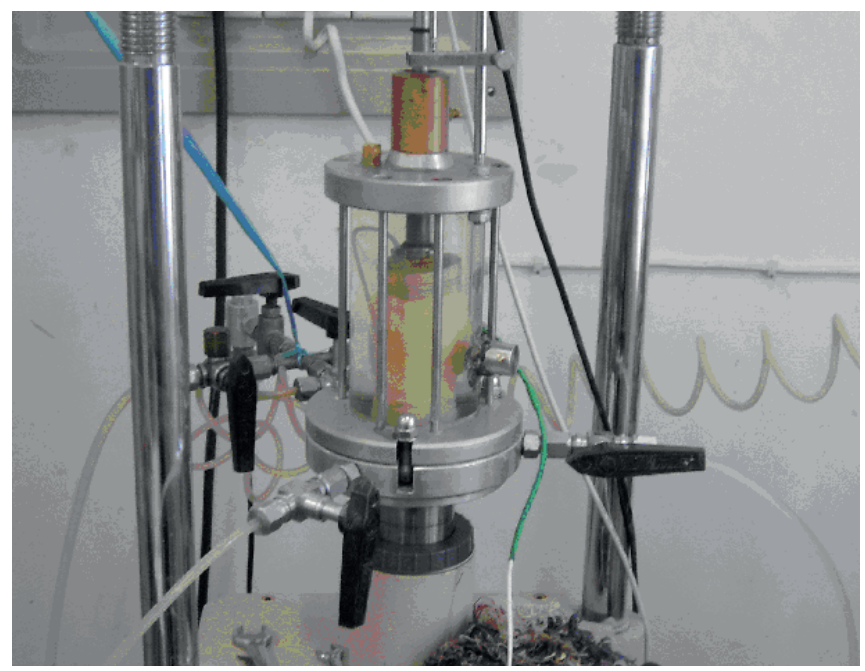

Fig. 5. Test photo

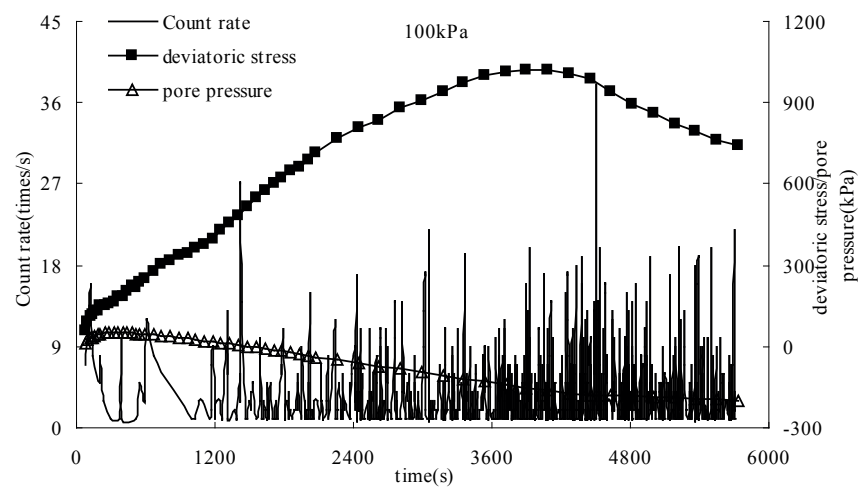

Fig. 6. AE's count rate, deviatoric stress \& pore pressure v.s. time

During the test, the loading system was controlled by the axial strain loading with certain velocity and the $\mathrm{AE}$ monitoring was kept with the loading process, in which the response frequency of AE sensor was $30.0 \mathrm{kHz}$.

The figure 4 and figure 5 were the diagram of acoustic emission testing of calcareous sand and the test photo.
The curve of count rate/deviatric stress/ pore pressure v.s. time was shown in figure 6.

From the figure 6, it showed that at the beginning of test, the sample volume of calcareous sands was reduced due to squeezing, and its particle was on the process of mutually biting, as a result, there was the AE signal with lower activities. With the increasing of deviatric stress, the calcareous sands' particle was crushed that resulted in the dilatant tendency of sample. At this stage there was the obvious activities of AE due to the particle crushing and mutual friction between particles. When the deviatric stress increased to the maximum, its dilatand tendency was weakened, but the particle crushing was continued to developed due to particle's friction, therefore the calcareous particle crushing played main role for its $\mathrm{AE}$ activities in this stage until to the end.

\section{AE MODEL FOE CALCAREOUS SANDS}

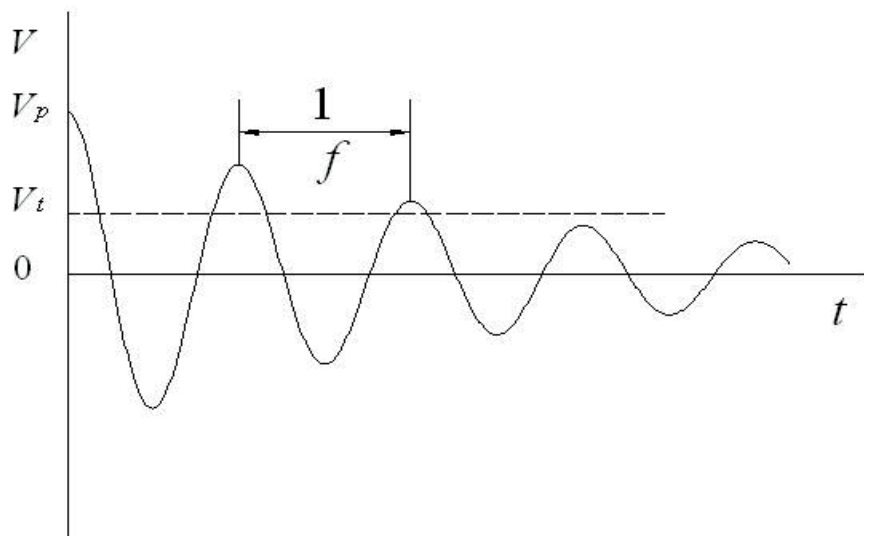

Fig.4 A. simplified decayed waveform of AE signal

The acoustic emission (AE) signal was the random from the apparatus during the test. Harris[23] thought that the AE signal outputted from the sensor was composed of damped cosine wave and its frequency was roughly equaled to the sensor's resonant frequency, shown in fig. 4.

The equation (1) was the signal voltage outputted from the sensor

$$
V=V_{P} e^{-\beta t} \cos 2 \pi f t
$$

In equation:

$V$ - the transient voltages,

$V_{P}$ - the peak voltage,

$\beta$ - the attenuation coefficient,

$t$ - the time

$f$ - the signal frequency that was roughly equaled to the sensor's resonant frequency.

If the threshold voltage was $V_{t}$, the equation (1) was evolved to equation (2), then the counts of a hit was described by equation (3). 


$$
\begin{aligned}
V & =V_{p} e^{-\beta \eta \frac{1}{f}} \cos \left[(2 \pi f) \eta \frac{1}{f}\right] \\
& =V_{P} e^{-\beta \eta \frac{1}{f}}
\end{aligned}
$$

From the equation (3):

the counts $\eta$ of a hit was related to the following factors:

$\beta$ - the attenuation coefficient,

$f$ - the frequency

$V_{P}$ - the peak voltage

$V_{t}$ - the threshold voltage

$$
\eta=\frac{f}{\beta} \ln \frac{V_{P}}{V_{t}}
$$

The study[24]for the ultrasonic attenuation experiment of rock showed that the ultrasonic attenuation coefficient was the ratio function of frequency, shown in equation (4).

$$
\beta=\frac{1}{A_{1}} f
$$

In equation:

$A_{1}$ - the constant.

If the $\mathrm{AE}$ wave was satisfied with the equation (3) and the equation (4), then the equation (5) was obtained.

$$
\eta=A_{1} \ln \frac{V_{P}}{V_{t}}
$$

For the above analysis, there were two hypotheses that the AE signal was roughly equaled to the attenuation cosine wave and $\underline{f}$ was the constants, but in fact, the attenuation wave was ${ }^{\beta}$ from the resonance of sensors, most of which was made from the piezoelectric, once contacted with the specimen, their frequency band was widened, which indicated that there is no obvious strong resonance. Under these circumstances, it was the specimen not the sensor that caused the attenuation. Therefore $\frac{f}{\beta}$ couldn't be a constant and related to the geometric shapes, sound source location and bearing state of specimen.

In the calcareous sand study[19], its particle breakage caused not only the plastic strain and energy consuming of specimen in the macro but also the particle smaller than before and the surface area increasing of specimen at the micro, therefore the particle breakage was closely related with the energy input. Under the condition of triaxial stress test, the particle breakage of the certain specimen was controlled by the combination of normal stress, shearing stress with related strain.

Under the condition of triaxial shearing, if the effective principal stress of specimen were $\sigma_{1} 、 \sigma_{2} 、 \sigma_{3} 、\left(\sigma_{2}-\sigma_{3}\right)$, its principal strain increment were $d \varepsilon_{1}, d \varepsilon_{2} 、 d \varepsilon_{3} 、\left(d \varepsilon_{1}-d \varepsilon_{3}\right)$, its volumetric strain increment was $d \varepsilon_{v}$, so its energy increment was described as the equation (6).

$$
\begin{aligned}
d E & =\sigma_{1}^{\prime} \cdot d \varepsilon_{1}+\sigma_{2}^{\prime} \cdot d \varepsilon_{2}+\sigma_{3}^{\prime} \cdot d \varepsilon_{3} \\
& =\sigma_{1}^{\prime} \cdot d \varepsilon_{1}+2 \sigma_{3}^{\prime} \cdot d \varepsilon_{3} \\
& =p^{\prime} \cdot d \varepsilon_{v}+q^{\prime} \cdot d \varepsilon_{s}
\end{aligned}
$$

In equation:

$$
\begin{aligned}
q^{\prime} & =\sigma_{1}^{\prime}-\sigma_{3}^{\prime} \\
p^{\prime} & =\frac{\sigma_{1}+2 \sigma_{3}}{3} \\
d \varepsilon_{v} & =d \varepsilon_{1}+2 d \varepsilon_{3} \\
d \varepsilon_{s} & =\frac{d \varepsilon_{1}-d \varepsilon_{v}}{3}
\end{aligned}
$$

In equation (6), the energy increment was divided into two parts: one was the recoverable elastic energy increment $(d E)_{e}$, the other was the unrecoverable plastic energy increment $(d E)_{P}$, therefore the equation (6) was deduced into the equation (7).

$$
d E=(d E)_{e}+(d E)_{P}
$$

In equation (7):

$$
\begin{aligned}
& (d E)_{e}=\left(p^{\prime} \cdot d \varepsilon_{v}+q^{\prime} \cdot d \varepsilon_{s}\right)_{e} \\
& (d E)_{P}=\left(p^{\prime} \cdot d \varepsilon_{v}+q^{\prime} \cdot d \varepsilon_{s}\right)_{P}
\end{aligned}
$$

According to the Roscoe hypothesis [25], $\left(q^{\prime} \cdot d \varepsilon_{s}\right)_{e}=0$, then equation (7) was deduced into the equation (8).

$$
\begin{aligned}
d E & =(d E)_{e}+(d E)_{P} \\
& =\left(p^{\prime} \cdot d \varepsilon_{v}\right)_{e}+\left(p^{\prime} \cdot d \varepsilon_{v}+q^{\prime} \cdot d \varepsilon_{s}\right)_{P}
\end{aligned}
$$

Because of the nonreversible process of particle breakage, though the stress and strain could return to certain state, the broken particle couldn't return to the original state, therefore on the triaxial shearing test process, the energy released by particles of calcareous sands could be expressed by equation (9):

$$
\begin{aligned}
E_{p} & =\int(d E)_{P} \\
& =\int\left(q^{\prime} \cdot d \varepsilon_{v}\right)_{P}+\int\left(p^{\prime} \cdot d \varepsilon_{v}\right)_{P}-\int\left(p^{\prime} \cdot d \varepsilon_{v}\right)_{e}
\end{aligned}
$$

During the compression and shearing process, on the one hand almost all deformation of calcareous sands particles was the plastic one, on the other hand the recoverable elastic energy from the average normal stress could be neglected, hence, the equation (9) was changed into equation (10). 


$$
\begin{aligned}
E_{p} & =\int(d E)_{P} \\
& =\int\left(q^{\prime} \cdot d \varepsilon_{s}\right)_{P}+\int\left(p^{\prime} \cdot d \varepsilon_{v}\right)_{P}
\end{aligned}
$$

It was supposed that most of the energy, $E_{P}$, released by the particle breakage of calcareous sands was turned into the acoustic energy $E_{A}$, so $E_{P} \approx E_{A}$, and the peak voltage $V_{P}$ outputted from the sensors square was direct proportion to the square root of plastic energy $E_{P}$, so the peak voltage was described by the equation (11).

$$
V_{P}=\psi \sqrt{E_{P}}
$$

In equation:

$\psi$ - the mechanical and electric constant.

Combined the equation (5) with (11), there was the equation (12).

$$
\eta=A_{1} \ln \left(\frac{\psi \sqrt{E_{P}}}{V_{t}}\right)
$$

During the triaxial shearing test of calcareous sands, the process of particle breakage was the process of AE pulse producing. For this process, it was variable, and $x$ was used to represent it, so the equation (12) was described by equation (13). Meanwhile the hits from the particle breakage of calcareous sands couldn't be a constant, but it could be describe the function of $x$, shown in equation (14).

$$
\begin{aligned}
& \eta=\eta(x) \\
& \phi=\phi(x)
\end{aligned}
$$

In equation:

$\phi$ - the hits.

For calcareous sands, its particle breakage was the random distribution value, therefore the hits related with particle breakage was also the random distribution value. It was supposed that the hits from the particle breakage of calcareous sands obeyed the Weibull distribution, so the equation (14) was deduced into equation (15).

$$
\phi(x)=\frac{m}{\alpha}\left(\frac{x^{m-1}}{\varepsilon}\right) e^{-\frac{x^{m}}{\alpha}}
$$

In equation, $m$ was the shape parameter of Weibull distribution, $\alpha$ was the scaling parameter of Weibull distribution.

It was supposed that $N(x)$ was the total number of pulse after it reached the process variable during the test, so the
$N(x)$ was not only the function of total number of pulse of one hit, but also the function of hits produced during the test, as a result during the triaxial shearing test of calcareous sands the total number of AE accounts could be described by equation (16). If the equation (16) was derivated by time, the AE rate of calcareous sands was described by equation (17), then if the equation (17) was combined with equation (10) and (15), the equation of $\mathrm{AE}$ rate based on the particle breakage of calcareous sands was obtained, shown in equation (18).

$$
\begin{aligned}
& N(x)=\int \eta(x) d \phi \\
& =A_{1} \int \ln \left(\frac{\psi \sqrt{E_{P}}}{V_{t}}\right)\left(\frac{d \phi}{d x}\right) d x \\
& \frac{d N}{d t}=\eta(x) \frac{d \phi}{d x} \frac{d x}{d t} \\
& =A_{1} \ln \frac{\psi \sqrt{E_{P}}}{V_{t}} \frac{d \phi}{d x} \frac{d x}{d t} \\
& \frac{d N}{d t}=\eta(x) \frac{d \phi}{d x} \frac{d x}{d t} \\
& =A_{1} \ln \frac{\psi \sqrt{\int\left(q^{\prime} \cdot d \varepsilon_{s}\right)_{P}+\int\left(p^{\prime} \cdot d \varepsilon_{v}\right)_{P}}}{V_{t}} \cdot \frac{d\left(\frac{m}{\alpha}\left(\frac{x^{m-1}}{\alpha}\right) e^{-\frac{x^{m}}{\alpha}}\right)}{d x} \frac{d x}{d t}
\end{aligned}
$$

\section{CONCLUSION}

The particle of calcareous sands was forced to crush, then the energy from the crushing was released by the form of sound waves. Therefore the AE technique was used to detect the calcareous sands AE signal when it crushed. According to the AE characteristics, the mechanics of calcareous sands was studied. Study showed that:

1) there was the AE activities on the low confining pressure condition at the beginnig of test,

2) there was more and more AE activities with the continuing of test until to the end,

3) the calcareous sands' AE activities was on the whole testing,

4) the calcareous sands' particle crushing and mutual friction played different roles for its AE activities. Then the AE model based on the calcarous sands' particle crushing was discussed.

\section{ACKNOWLEDGEMENTS}

The study was supported by The National Natural Science Foundation of China; Foundation Number: 41572297. 973 Program of science and Technology Department, No.2013CB956104. National Science and technology support program, No.2014BAC01B01. 


\section{BIBLIOGRAPHY}

1. YANG Rui-feng, MA Tie-hua.A Study on the Applications of Acoustic Emission Technique. JOURNAL OF NORTH UNIVERSITY of CHINA (NATURAL SCIENCE EDITION), Vol. 27,NO. 5,pp. 456-461, 2006.

2. Feng Xiating (Translation). Application of Accoustic Emission technology(in Chinese). Beijing: Metallurgical Industry Press; 1996.

3. Xu Bingfeng. application of AE Technology in geotechnical engineering. Nanjing: Hohai University, 1989.

4. R.M.Koerner, A.E.Lord,Jr.. Acoustic Emission in Medium Plasticity Clay Silt. Journal of the Soil Mecanicas and Foundations Division, Proceedings of the American Society of Civil Engineering, Vol.98,NO.SM1,1972.

5. R.M.Koerner, A.E.Lord,Jr., W.Martin Mccabe, and J.W.Curran. Acoustic Emission Behavour of Granular Solis. Journal of Geotechnical Engineering Division,ASCE,Vol.102.NO.GT7,1976.

6. R.M.Koerner, A.E.Lord,Jr. Acoustic Emission Monitoring of Earth Dam Stability. Water Power \& Dam Construction 1976.

7. R.M.Koerner, A.E.Lord,Jr., W.Martin Mccabe. Acoustic Emission Behavour of Cohesive Solis. Journal of Geotechnical Engineering Division,ASCE,Vol.103.NO.GT8,1977.

8. R.M.Koerner, J.S.Reif, and M.J.Burlingame. Detection Methods for Location of Subsurface Water and Seepage. Journal of Geotechnical Engineering Division,ASCE,Vol.105.NO.GT11,1979.

9. R.M.Koerner, W.M.Mccabe, and Luis F.Baldivieso. Acoustic Emission Monitoring of seepage. Journal of Geotechnical Engineering Division, Proceedings of the American Society of Civil Engineering, Vol.107.NO.GT4,1981.

10. Koerner, R.M., Mccabe, W.M., and Lord, A.E.. Acoustic Emission Behavour and Montoring of Soils. Acoustic Emission in Geotechnical Engineering Practice, ASTM STP 750, V.P. Drntvich and R.E.Gray. Eds., American Society for Testing and Materials,1981.

11. W.C.B.Villet, J.K.Mitchell, and P.T.Tringale. Acoustic Emissions Generated During the Qusai-static Cone Penetration of Soils. Acoustic Emissions in Geotechnical Engineering Practice, ASTM, STP750,V.P.Drnevich and R.E.Gray, EDs.. American Society for Testing and Materials,1981.
12. K.Tanimoto and J.Nakamure. Studies of Acoustic Emission in soils. Acoustic Emissions in Geotechnical Engineering Practice, ASTM, STP750,V.P.Drnevich and R.E.Gray, EDs. American Society for Testing and Materials,1981.

13. R.M.Koerner,A.E.Lord,Jr., and W.L.Deutsch. Determination of Prestress in Granular Soils Using AE. Jounrnal of Geotechnical Engineering, Vol,110,NO.3,1984.

14. R.M.Koerner, A.E.Lord,Jr., and W.L.Deutsch. Determination of Prestress in Cohesive Soils Using AE. Jounrnal of Geotechnical Engineering, Vol,110,NO.11,1984,ASCE.

15. K.Tanimoto and J.Nakamure. Yielding of Soils as Determined by Acoustic Emission. Soils and Foundations, Vol.26.NO.3,1986.

16. W.L.Deutsch, R.M.Koerner, A.E.Lord,Jr.. Determination of Prestress of In-Situ Soils using Acoustic Emissions. Journal of Geotechnical Engineering Division,ASCE,Vol.115, NO.2,1988.

17. Xu Bingfeng, Qian Jiahuan, Zhu Zhangya,et.. LABORATORY STUDY ON ACOUST1(2 EM ISSION MONITORING OF SOIL FLOW, Dam Observation and Geotechnical Tests, Vol.19, NO.1, pp, 32-36,1995.

18. The comprehensive scientific expedition of Chinese Academy of Sciences in Nansha Island, Quaternary Coral Reef Geology of Yongshu Reef, Nansha Island.Beijing: Science, 1992.

19. Jia-ming Zhang, Study on the fundamental mechanical characteristics of calcareous sand and the influence of particle breakage, Wuhan: Wuhan Institute of Rock \& Soil Mechanics, Chinese Academy of Sciences, P.R. China, 2004.

20. ZHANG Jiaming,WANG Ren, SHI Xiangfeng, etc.. COMPRESSION AND CRUSHING BEHAVIOR oF CALCAREOUS SAND UNDER CONFINED COM PRESSION, Chinese Journal of Rock Mechanics and Engineering, Vol. 24, NO.18, pp.3327-3331, 2005.

21. Jinping $\mathrm{Wu}, Y a o \mathrm{Zhu}$, Zhigang Lou. Influence of Particle Breakage ON Deformation and Strength Properties of Calcareous Sands, chinese Journal of Geotechnical Engineering, Vol. 19, NO.5, pp. 49-55,1997.

22. Lv Haibo, Wang Ren, Kong Lingwei. PERLIMINARY MESOSCOPIC ANALYSIS ON FACTORS OF BREAKAGE CALCAREOUS SOIL, Chinese Journal of Rock Mechanics and Engineering, Vol. 20, NO.Suup., pp, 890 982,2001.

23. Haeeis D., Tetelman A. S., Darwish F.. Acoustic Emission Testing. ASTM, Philadelphia, SPT505,1972. 
24. LI Zaoding, LIU Zhongmin, ZHAO Yijun. Experimental Study on Ultrasonic attenuation in rock, Journal of China Coal Society, NO.1, pp, 45-53,1987.

25. Cao Qinglin, Yu Kesheng, Sang Yufa. INTELLIGENT PREDICT1ON OF ROOF FALL BY AE TECHNIQUE. THE CHINESE JOURNAL OF NONFERROUS METALS; Vol. 6, NO.2, pp,7-12, 1996.

\section{CONTACT WITH THE AUTHORS}

Fengyi TAN

e-mail:tfy2003@126.com

tel.: 86-13677142166

Yangtze River scientific Research Institute Wuhan Hubei, 430015

China 